\title{
Availability, use and quality of care for medical abortion services-Preliminary results of two components: KIIs and the Pharmacy Study
}

Wilson Liambila

Population Council

Harriet Birungi

Population Council

Francis Onyango

Population Council

Brian Mdawida

Population Council

Vitalis Akora

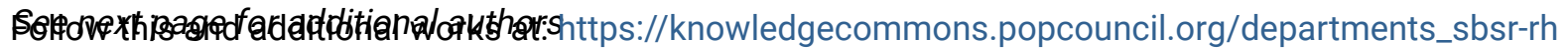

Part of the International Public Health Commons, Maternal and Child Health Commons, Obstetrics and Gynecology Commons, Social and Behavioral Sciences Commons, and the Women's Health Commons

How does access to this work benefit you? Let us know!

\section{Recommended Citation}

Liambila, Wilson, Harriet Birungi, Francis Onyango, Brian Mdawida, Vitalis Akora, Thoai Ngo, and Kate Reiss. 2013. "Availability, use and quality of care for medical abortion services-Preliminary results of two components: KIls and the Pharmacy Study," presentation at the 2nd Annual Scientific Conference organized by the Reproductive Health Network (RHN) Kisumu, Kenya. 


\section{Authors}

Wilson Liambila, Harriet Birungi, Francis Onyango, Brian Mdawida, Vitalis Akora, Thoai Ngo, and Kate Reiss 


\section{AVAILABILITY, USE AND QUALITY OF CARE FOR MEDICAL ABORTION SERVICES}

\section{Preliminary Results of two components: KIls and the Pharmacy Study}

Population Council:

Wilson Liambila, Harriet Birungi; Francis Onyango and Brian Mdawida.

Marie Stopes

Vitalis Akora, Thoai Ngo and Kate Reiss 


\section{BACKGROUND}

- Presentation - part of activities being implemented under The STEP UP (Strengthening Evidence for Programming on Unintended Pregnancy)

Research Programme Consortium, which generates policy-relevant research to promote an evidencebased approach for improving access to FP and safe abortion.

- STEP UP focuses its activities in five countries: Bangladesh, Ghana, India, Kenya, and Senegal.

- STEP UP is coordinated by PC in partnership with APHRC; ICDDR,B; the LSH\&TM ; MSI/MSK and Partners in Population and Development (PPD). Funded by UK-aid 


\section{Opportunities/Problem Statement}

- Renewed interest in MM and unsafe abortion since 2010 (New Const. Expansion of MA services), MDG5

- The incidence and complications of unsafe abortion report-shows high incid.464,690 induced abortions in Kenya in 2012 (rate: 48/1000 women- 15-49 yrs

- In Kenya, little is known about:

$\checkmark$ The private sector provision of MAS,

$\checkmark$ Acceptability of MAS among Pharmacy staff and clients, and the content of care offered

$\checkmark$ QOC for MA services in the Private Sector clinics

$\checkmark$ Provision of FP services in the Private Sector HFs 


\section{Opportunities - Many resources now available to support safe abortion services}
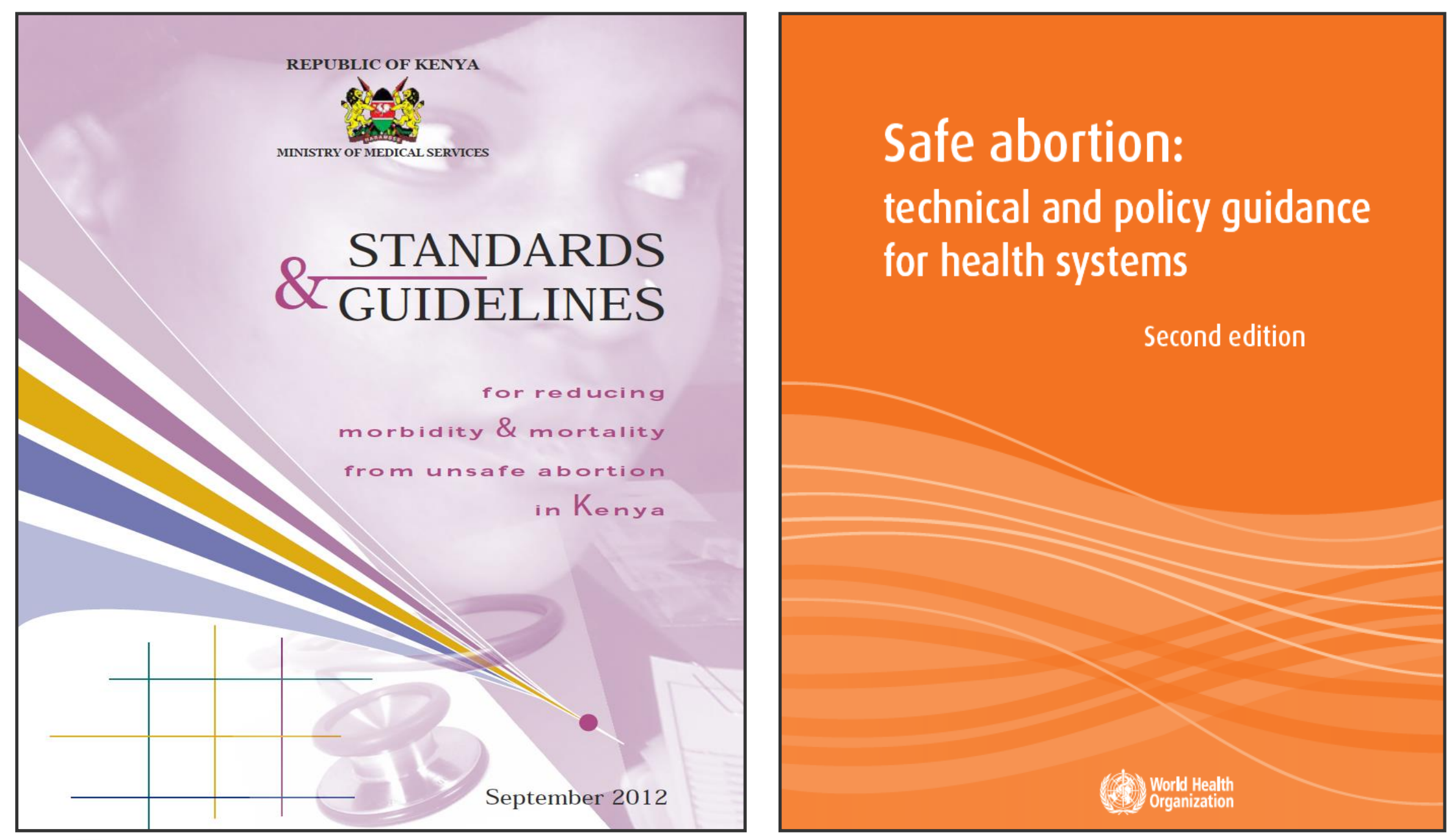


\section{STEP-UP in Kenya - what are we doing?}

Output 1: A coherent body of robust research based evidence generated to address STEP UP's priority areas.

$>$ Developing a conceptual framework for UP

$>$ Building the evidence base for understanding UP in Kenya - Country Profile (APHRC, PC, PPD)

$>$ Addressing UP among adolescents girls living in urban slums of Kenya (APHRC, MSK)

$>$ Assessing the use, availability and quality of care for medical abortion services in Kenya (PC, MSK, RHN) 


\section{Objectives of the project}

a) Determine the activities being undertaken to support the expansion of MA services,

b) Determine the preparedness of private facilities to provide MA services to clients

c) Assess the availability and provision practices of misoprostol \& mifepristone in private outlets; and

d) Explore the information given to clients seeking MAS at private clinics and pharmacies 


\section{STUDY DESIGN \& METHODOLOGY}

- Cross-sectional exploratory study

- Three components

$\checkmark$ KIIs (Policy Makers and prog.mgrs -NBO, KSM)

$\checkmark$ Pharmacy study

$\checkmark$ Clinic-based study (Not covered in this presentation)

- Study sites (Kisumu, Nairobi and Mombasa)

- Data collection

$\checkmark$ Individual interviews held with Snr mgrs (19)

$\checkmark$ Structured interviews with pharmacy/ass.(235)

$\checkmark$ MCs (100pharmacies-i.e.appr.33/site= 400visits) 


\section{.........Key Issues Explored}

Key Informant Interviews:

New Const; opportunities, challenges, interventions, M/E; QOC, Capacity building, public HFs \& Advocacy Pharmacy assistant interviews:

Background characteristics, Training and knowledge, service provision, FP services, cost of drugs for MA

\section{Simulated clients:}

Assume specific roles of real clients seeking MA services, ask for services in the assumed role, observe the provider's ability to respond to the needs of SCs \& complete a short tool immediately after visit 


\section{FINDINGS}

1) Key Informant Interviews - KIIs

- The 2010 new const. has provided a new supportive legal framework

- S/Abortion services are now more available

- Peoples' perceptions regarding abortion changing.

- However, negative attitudes and beliefs still persist among HWs, police; judiciary the public.

- There is still some apprehension to provide MA services in the public sector facilities. 
2) Pharmacy Assistant interviews:

\section{Age Distribution of Pharmacy Assistants}

Age

$22-30$ yrs

$31-40$ yrs

$>41 y r s$

$$
\mathbf{N}=\mathbf{2 3 5}
$$

n

140

81

14

Total
$\%$

59.6

34.4

6.0

100.0 


\section{Education Levels of PAs}

\section{Education Level}

Primary

Secondary

College

University

\section{$\mathbf{N}=\mathbf{2 3 5}$}

\begin{tabular}{c|c}
$\mathbf{n}$ & \% \\
5 & $(2.1)$ \\
11 & $(4.7)$ \\
191 & $(81.3)$ \\
28 & $(11.9)$ \\
$\mathbf{2 3 5}$ & $\mathbf{( 1 0 0 . 0 )}$
\end{tabular}




\section{Trained in TOP services}

\section{Position}

owner

Manager

Employee

\section{$\mathbf{N}=\mathbf{2 3 5}$}

n

$\%$

(1.3)

$(0.4)$

28

(11.9)

32 


\section{Only a few clients who purchased Miso/Mife were provided with an FP Method}

\begin{tabular}{l|c|c|c}
\begin{tabular}{l|c|} 
Does the Pharmacy Sell? \\
(YES)
\end{tabular} & \multicolumn{2}{|c|}{$\mathbf{N = 2 1 5}$} & $\begin{array}{c}\text { Pur. Miso, } \\
\text { Mife \& FP }\end{array}$ \\
\hline Male Condom & $\mathbf{n}$ & $\mathbf{\%}$ & $\mathbf{n = 5}$ \\
Female Condom & 53 & 93. & 1 \\
Pills & 213 & $\mathbf{2 5}$ & 1 \\
Diaphgram & 16 & 7 & 1 \\
Foam Pills & 22 & 10 & 0 \\
Injectables(3 Months) & 163 & 76 & 1 \\
Injectables (2 Months) & 24 & 11 & 0 \\
Implants/Jadelle & 36 & 17 & 1 \\
EC & 201 & 94 & 0 \\
Miso/Mife or Comb $(\mathbf{N = 2 3 4 )}$ & $\mathbf{2 6}$ & $\mathbf{( 1 1 )}$ &
\end{tabular}


3) Results of Mystery Client Experiences With Pharmacy Assistants

Number of Visits made by MC by scenario

\section{Client Scenario}

Wants misoprostol

Pregnant \& seeking help to end it

Seeking medication to end 2 months pregnancy

Seeking medication to end 12 weeks (3months) pregnancy

Total
$\mathbf{N}=\mathbf{4 0 1}$
n
101
100
101
25.2
99
$401 \quad 100.0$ 


\section{Number of staff MCs interacted with}

\begin{tabular}{|c|c|c|c|c|c|c|}
\hline \multirow{3}{*}{ Client Scenario } & \multicolumn{6}{|c|}{ No. of staff MCs interacted with } \\
\hline & 1 & $\%$ & 2 & $\%$ & $\begin{array}{l}3 \text { or } \\
\text { more }\end{array}$ & $\%$ \\
\hline & 309 & 82 & 61 & 16 & 7 & 2 \\
\hline Wants misoprostol & 87 & 86 & 12 & 12 & 1 & 1 \\
\hline $\begin{array}{l}\text { Pregnant and seeking } \\
\text { help to end it }\end{array}$ & 65 & 65 & 19 & 19 & 1 & 1 \\
\hline $\begin{array}{l}\text { Seeking medication to } \\
\text { end } 2 \text { months pregnancy }\end{array}$ & 78 & 77 & 12 & 12 & 4 & 4 \\
\hline $\begin{array}{l}\text { Seeking medication to } \\
\text { end } 3 \text { months pregnancy }\end{array}$ & 79 & 80 & 18 & 18 & 1 & 1 \\
\hline
\end{tabular}




\section{History Taking and Screening}

\section{Client Scenario}

Staff asked about:

LMP

Gestation age

Medical History

Age

SES

Reasons for

termination

Prescription from

$\mathrm{m} /$ practitioner

Proof of permission from 3rd Parties

\section{1}

101

7

29

0

6

4

14

45

45

24

24

0

2

100

39

50

6

26

40

\begin{tabular}{l|l}
$57 \quad 57$
\end{tabular}

03

3
3

101

33

76

2

24

31

49

14

13 \begin{tabular}{l|l|l}
14 & 33 & 33
\end{tabular}

\begin{tabular}{l|l}
$14 \quad 33$ & 33
\end{tabular}

13

4

$99 \%$

$\begin{array}{lll}33 & 74 & 75\end{array}$

\begin{tabular}{l|l|l}
75 & 64 & 65
\end{tabular}

$\begin{array}{lll}2 & 18 & 18\end{array}$

\begin{tabular}{l|l|l}
24 & 38 & 38
\end{tabular}

\begin{tabular}{l|l|l}
31 & 37 & 37
\end{tabular}

\begin{tabular}{l|l|l}
49 & 65 & 66
\end{tabular}

$28 \quad 28$ 


\section{Service Provision By Scenario}

\section{Client Scenario}

Staff Advised on:

Continuing with Pregnancy

Seeking counseling before TOP

Where to obtain services TOP

Available TOP methods

$\begin{array}{llllllll}28 & 28 & 50 & 50 & 54 & 53 & 69 & 70\end{array}$ 


\section{Service Provision: Does Knowing ones SES influence Method type?}

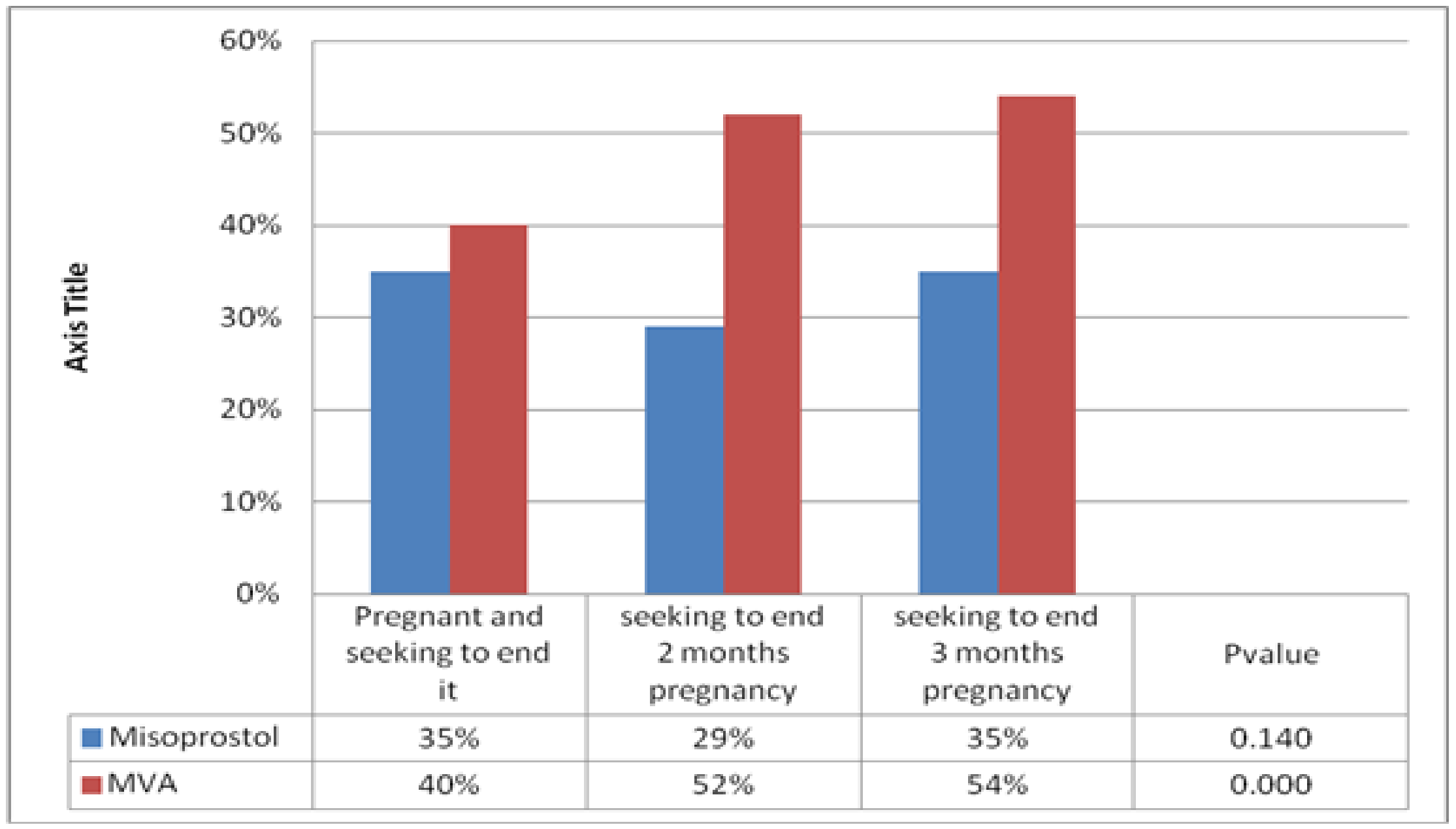




\section{For MA medications offered, pharmacy staff explained...}

Client Scenario

\section{1}

$101 \%$

When to use med

How to take med

How med. works

Side-effects of med

Effectiveness

When to seek help

Complications

Where to seek help

$5 \quad 5$

$5 \quad 5$

6

$22 \quad 22$

9

3

12

3

\section{2}

3

4

100

$\%$

101

$\%$

$99 \%$

6

6

19

19

$12 \quad 12$

19

19

22

22

$14 \quad 14$

20

20

23

23

$16 \quad 16$

18

18

11

11

$10 \quad 10$

13

13

11

3

9

17

6

6

13

11

1616

\begin{tabular}{l|l|l}
9 & 8 & 8
\end{tabular}

17

13

9

9

\begin{tabular}{|l|l|l|l|}
6 & 6 & 11 & 11
\end{tabular}




\section{Staff rarely discussed FP with their clients}

\section{Did the pharmacy staff?}

$\mathrm{N}=401$

Discuss Family Planning

n

48

12

Recommend Family Planning

37

8.7

Provide FP method

2

0.5

Refer client elsewhere for FP method 


\section{FP rarely discussed across Scenarios}

\begin{tabular}{|c|c|c|c|c|c|c|c|c|}
\hline \multirow{2}{*}{$\begin{array}{l}\text { Did the } \\
\text { Pharmacy } \\
\text { Staff...... } \\
\text { Client } \\
\text { Scenario }\end{array}$} & \multicolumn{2}{|c|}{$\begin{array}{l}\text { Discuss } \\
\text { FP? }\end{array}$} & \multicolumn{2}{|c|}{$\begin{array}{l}\text { Recom } \\
\text { mend FP? }\end{array}$} & \multicolumn{2}{|c|}{$\begin{array}{l}\text { Give FP } \\
\text { method? }\end{array}$} & \multicolumn{2}{|c|}{$\begin{array}{l}\text { Refer } \\
\text { client for } \\
\text { FP? }\end{array}$} \\
\hline & $\begin{aligned} & n \\
= & 101\end{aligned}$ & $\%$ & $\begin{array}{c}n \\
=100\end{array}$ & $\%$ & $\begin{array}{c}n \\
=101\end{array}$ & $\%$ & $\begin{aligned} & \mathbf{n} \\
= & 99\end{aligned}$ & $\%$ \\
\hline $\begin{array}{l}\text { Wants } \\
\text { misoprostol }\end{array}$ & 6 & 6 & 5 & 5 & 0 & 0 & 0 & 0 \\
\hline $\begin{array}{l}\text { Preg. \& seeking } \\
\text { help to end it }\end{array}$ & 7 & 7 & 7 & 7 & 1 & 1 & 1 & 1 \\
\hline $\begin{array}{l}\text { Seeking med.to } \\
\text { end } 2 / 12 \text { preg. }\end{array}$ & 19 & 19 & 11 & 11 & 0 & 0 & 0 & 0 \\
\hline $\begin{array}{l}\text { Seeking med. } \\
\text { to end } 3 / 12 \\
\text { pregnancy }\end{array}$ & 16 & 16 & 12 & 12 & 1 & 1 & 3 & 3 \\
\hline
\end{tabular}


4. Experiences

Observed by RAs

(during Data

Collection) on provision

of MA services to

clients 


\section{Decliners and Acceptors had different reasons for their positions}

- Some of the reasons given by decliners:

- "Abortion is illegal, morally wrong"

- "Not trained any body in this service

- "We lack appropriate drugs"

- 'Due to personal beliefs: "Abortion kills" "It is a big sin", "God is against killing"

- Acceptors:

$\checkmark$ Should be legalized

$\checkmark$ "the study will help Govt. improve policies"

$\checkmark$ "Improves lives of women: Reduces Mmorb/mort $\checkmark$ "Abortion also protects the interests of children" 


\section{Interactions/Counseling dominated by Money}

$>$ None mentioned health issues. They were concerned with money to be paid. BM RA-MBS

$>$ "I was given more information when I promised to raise half the amount. LO RA-KSM

$>$ Clients were assisted when they informed the provider of money they had. HM RA-NRB (QC)

$>$ Reluctant to use medical abortion methods. (Preference for surgical methods).

> "Some providers would let us know that this was a business for making money apart from helping". FMM RA-NRB (QC) 


\section{Providers' Attitude and Values (FP)}

- Some PAs were judgmental and seem to suggest that there wasn't any need for FP since 'the damage had been done already'. Examples:

$\checkmark$ Tumalizane na abortion kwanza, FP haiwezi kukusaidia (Let us first of all finish with the business of Abortion, FP can not help you) $L O$ (RA-KSM).

$\checkmark$ "You should have thought about it before you got yourself in such a mess,". BM (RA-MBS)

$\checkmark$ "Couldn't you think of using condoms, FP is not my concern" SB (RA-NRB)

$\checkmark$ "What method were you using? Did it backfire on you?"VA (RA-NRB) 


\section{CONCLUSION \& RECOMMENDATIONS}

- Abortion environment - changes since 2010.

- Safe abortion services more available now

- However, challenges/barriers still remain (stigma, inadequate HPs, commodities, ignorance of the law \& lack of pol/direction)

- Preparedness of pharmacies to provide MA low

- Overall sales of miso \& mife were low

- Very few clients (out of those who sought $M A$ ) received FP services 


\section{RECOMMENDATIONS CONT'D}

- $\mathrm{MOH}$ to provide a clear policy statement on safe abortion services,

- Dissemination of s/and guidelines for managing unsafe abortion/ training of HPs,

- Awareness creation (community level and within the public sector) to reduce "fear".

- Need to make commodities for SA available

- Increase the capacity of HPs in CAC services

- Expand training of HPs in VCAT for MA \& FP 


\section{Thank You!}

\& now time for

Questions and Issues

for clarification 